\title{
Eficiência de acessos de Cucurbita maxima como polinizadores de abóbo- ra híbrida do tipo "Tetsukabuto"
}

\author{
Warley Marcos Nascimento; Karuliny G Coimbra; Raquel A Freitas; Leonardo S Boiteux \\ Embrapa Hortaliças, C. Postal 218, 70359-970 Brasília-DF; wmn@cnph.embrapa.br
}

\section{RESUMO}

A abóbora tipo "Tetsukabuto" é um híbrido interespecífico, macho estéril, resultante do cruzamento entre Cucurbita maxima e $C$. moschata. Uma das estratégias utilizadas para produção comercial de frutos de "Tetsukabuto" tem sido o plantio adjacente e concomitante de acessos de C. maxima ou C. moschata como polinizadores. Este trabalho teve por objetivo avaliar a eficiência de diferentes acessos de C. maxima como fontes de pólen para produção comercial de abóbora tipo "Tetsukabuto". A cultivar de moranga 'Exposição' e o acesso 'Nirvana' foram utilizados como polinizadores para produção de frutos de dois híbridos do tipo varietal "Tetsukabuto" ('Jabras' e 'Kyoto'). Foram avaliados os tratamentos (cruzamentos) Jabras $x$ Exposição, Jabras $x$ Nirvana, Tetsukabuto $x$ Exposição, Tetsukabuto $x$ Nirvana, em quatro repetições. Foram determinados os parâmetros massa dos frutos, diâmetro dos frutos, espessura da polpa, número e massa de sementes. O acesso 'Nirvana' (cultivar em fase de validação) pode ser utilizado na produção comercial como polinizador de abóboras deste grupo varietal sem nenhum prejuízo quando comparado com a moranga 'Exposição'.

Palavras-chave: Curcubita maxima, Curcubita moschata, produção de híbridos, qualidade de sementes.

\section{ABSTRACT}

Efficiency of Cucurbita maxima accessions as pollinators in the commercial production of pumpkin ('Tetsukabuto' type)

'Tetsukabuto' pumpkins are interspecific hybrids between Cucurbita maxima $x$ C. moschata accessions. Such hybrids, however, are often male-sterile due to the impaired ability of the staminate flowers to produce functional pollen. The use of intervening rows of staminate (pollen-donor) plants is one strategy employed in order to have commercial fruit production. In the present work, two $C$. maxima accessions ['Exposição' (E) and 'Nirvana' (N)] were employed as pollen-donors (staminate parents) and their efficiency was compared considering fruit and seed yield parameters. Two pistillate Tetsukabuto hybrids ['Jabras' (J) and 'Kyoto Tetsukabuto' $(\mathrm{KT})]$ were employed in four possible unidirectional crosses ( $\mathrm{J} x \mathrm{E}$, $\mathrm{J} x \mathrm{~N}$, KT $x$ E and KT $x \mathrm{~N}$ ). Fruits were produced using standard manual pollination techniques done on a daily basis (during the morning). After harvesting, the following traits were evaluated: fruit weight, fruit diameter, fruit flesh depth, number of seeds per fruit and total seed weight. The results indicated that both staminate parents are equivalent for all traits. The accession 'Nirvana' (a cultivar in a pre-release stage) could be considered a commercial alternative to 'Exposição' (the traditional staminate parent under Brazilian conditions) due to its improved fruit quality attributes, which could provide an additional source of revenues for the 'Tetsukabuto' growers.

Keywords: Curcubita maxima, Curcubita moschata, hybrid production, seed quality.

(Recebido para publicação em 18 de junho de 2008; aceito em 15 de setembro de 2008)

(Received in June 18, 2008; accepted in September 15, 2008)

\begin{abstract}
A abóbora híbrida "Tetsukabuto", também denominada abóbora japonesa ou cabotiá, é resultante do cruzamento entre linhagens selecionadas de moranga (Cucurbita maxima Duch.) - empregadas como genitores femininos - e linhagens de abóbora (C. moschata Duch. et Poir.), empregadas como genitores masculinos (Amarante et al., 1994; Bisognin, 2002).

Híbridos pertencentes a este grupo varietal, originário de programas de melhoramento genético implementados no Japão (Robinson \& Decker-Walters, 1997), revelaram excelente adaptação ao cultivo no Brasil (Pereira, 1999). Atualmente, as abóboras do tipo "Tetsukatuto" ocupam o sétimo lugar dentre as hortaliças em cultivadas no Brasil (Pereira, 1999).
\end{abstract}

As formas híbridas "Tetsukabuto" possuem elevada importância sócio-econômica em diferentes regiões do país, com expressiva área plantada, devido a uma série de características positivas, tais como rusticidade, precocidade, uniformidade, elevado potencial produtivo, qualidade organoléptica (incluindo textura, sabor e reduzido tempo de cozimento) e prolongada conservação pós-colheita quando comparada com cultivares locais de polinização aberta (Tavares, 1999).

Os híbridos interespecíficos do tipo "Tetsukabuto" possuem flores masculinas estéreis, necessitando, para sua frutificação adequada, de técnicas indutoras de partenocarpia via aplicação de reguladores de crescimento (Pereira,
1999; Pasqualetto et al., 2001) ou do plantio simultâneo de plantas polinizadoras (Pedrosa et al., 1982). Várias são as cultivares polinizadoras utilizadas na produção comercial de frutos de abóbora híbrida, as quais podem ocupar até $20 \%$ da área cultivada. Estudos realizados na região do Distrito $\mathrm{Fe}$ deral revelaram maior eficiência da cultivar de moranga 'Exposição' na formação e na produção dos frutos da abóbora híbrida "Tetsukabuto". A maior eficiência da moranga 'Exposição' está diretamente relacionada com a sua grande produção de pólen, que aumenta as chances de fecundação dos frutos das plantas femininas pelos insetos polinizadores e resulta em maior freqüência no número de frutos comerciais 
em condições de campo (Pereira, 1999). A cultivar 'Exposição', entretanto, possui baixo valor de mercado dos seus frutos, sendo, em alguns casos, destinados à alimentação animal.

Estudos comparativos de variedades polinizadoras de híbridos "Tetsukabuto" são escassos na literatura. Neste contexto, alguns novos genótipos estão sendo desenvolvidos pelo programa de melhoramento da Embrapa Hortaliças visando agregar valor à produção de frutos das cultivares polinizadoras de híbridos "Tetsukabuto". Um acesso de $C$. maxima, denominado 'Nirvana', foi considerado promissor, em decorrência de suas características de coloração extremamente atrativas da casca e polpa dos frutos, contendo teores mais elevados de alfa e beta-caroteno e boas características organolépticas (textura e sabor). Este tipo de moranga poderia ser utilizado como uma polinizadora alternativa, agregando, desta forma, maior valor às plantações de "Tetsukabuto".

Este trabalho teve como objetivo comparar a eficiência de dois acessos de C. maxima como fontes de pólen para produção comercial de abóbora híbrida tipo "Tetsukabuto".

\section{MATERIAL E MÉTODOS}

Foi implementado, na Embrapa Hortaliças, um ensaio em telado, de setembro a dezembro de 2005 , visando avaliar a eficiência relativa de polinização na produção comercial de abóbora tipo 'Tetsukabuto' de dois acessos de moranga: 'Nirvana' (Embrapa Hortaliças) e 'Exposição' (Horticeres). O experimento foi instalado em delineamento inteiramente casualizado com quatro repetições. Foram utilizados como genitores femininos dois híbridos "Tetsukabuto": 'Jabras' (Embrapa Hortaliças) e 'Tetsukabuto' (Kyoto). A disposição no telado foi de 1:2, ou seja, uma linha de cada um dos polinizadores para duas linhas de 'Jabras' e duas linhas de 'Tetsukabuto' (Kyoto), sendo estas dispostas de maneira alternada. Desta forma, o ensaio foi composto pelos tratamentos (cruzamentos) 'Jabras' $x$ 'Exposição'; 'Jabras' $x$ 'Nirvana'; 'Tetsukabuto Kyoto' $x$ 'Exposição', 'Tetsukabuto Kyoto' $x$ 'Nirvana', em

Tabela 1. Características dos frutos de dois híbridos de abóbora tipo "Tetsukabuto" ('Jabras' e 'Tetsukabuto Kyoto - TK') polinizados por dois acessos ('Exposição' e 'Nirvana') de moranga (Cucurbita maxima). (fruit characteristics of 'Tetsukabuto' type pumpkin hybrids ('Jabras' and 'Tetsukabuto Kyoto-TK') pollinated by two squash (Cucurbita maxima) accessions ('Exposição' and 'Nirvana'). Brasília, Embrapa Hortaliças, 2005.

\begin{tabular}{|c|c|c|c|c|c|}
\hline Tratamentos & $\begin{array}{l}\text { Massa de } \\
\text { fruto (kg) }\end{array}$ & $\begin{array}{l}\text { Diâmetro do } \\
\text { fruto }(\mathrm{cm})\end{array}$ & $\begin{array}{l}\text { Espessura da } \\
\text { polpa }(\mathrm{cm})\end{array}$ & $\begin{array}{l}\text { Número de } \\
\text { sementes }\end{array}$ & $\begin{array}{l}\text { Massa de } \\
\text { sementes (g) }\end{array}$ \\
\hline TK x Nirvana & $1,23 \mathrm{a}$ & $14,90 \mathrm{a}$ & $2,53 \mathrm{a}$ & 70,75 a & 9,85 a \\
\hline TK x Exposição & 1,35 a & $16,06 \mathrm{a}$ & $2,53 \mathrm{a}$ & 73,75 a & $11,03 \mathrm{a}$ \\
\hline Jabras x Nirvana & $1,19 a$ & $14,27 \mathrm{a}$ & $2,53 \mathrm{a}$ & $94,00 \mathrm{a}$ & $13,64 a$ \\
\hline Jabras x Exposição & 1,23 a & 15,76 a & 2,95 a & $87,50 \mathrm{a}$ & $14,42 \mathrm{a}$ \\
\hline C.V. ( $\%)$ & 13,85 & 11,81 & 9,89 & 15,35 & 19,22 \\
\hline
\end{tabular}

Médias seguidas pela mesma letra, na coluna, não diferem entre si pelo teste Tukey a 5\% de probabilidade. (means followed by the same letter within a column are not significantly different according to Tukey's test at $\mathrm{p}<0.05$ ).

quatro repetições.

A semeadura dos acessos polinizadores foi realizada 15 dias antes da semeadura dos híbridos, visando assegurar a sincronia com o período de florescimento destes materiais genéticos (Pessoa, 1998). Os tratos culturais realizados seguiram as mesmas exigências do cultivo da cultura da abóbora, sendo os ramos principais tutorados e os secundários desbrotados. O florescimento iniciou aproximadamente 35 dias após a semeadura. A polinização manual foi realizada diariamente no período da manhã. Foi utilizada a proporção de flores de 1:1, ou seja, uma flor do polinizador para cada flor a ser polinizada, fornecendo assim, condições de igualdade de polinização. Este processo teve duração de aproximadamente 60 dias, quando se procedeu a colheita dos frutos. Após a colheita, os frutos foram avaliados quanto à qualidade e à eficiência de polinização. Foram analisadas as características massa dos frutos $(\mathrm{kg})$, diâmetro dos frutos $(\mathrm{cm})$, espessura da polpa $(\mathrm{cm})$, número de sementes por fruto e massa de sementes secas por fruto $(\mathrm{g})$. Os dados obtidos foram submetidos à análise de variância e as médias dos tratamentos comparadas pelo teste Tukey em 5\% de probabilidade.

\section{RESULTADOS E DISCUSSÃO}

Os tratamentos (duas cultivares de morangas utilizadas como polinizadores para produção comercial de abóboras tipo 'Tetsukabuto') não diferiram esta- tisticamente entre si em nenhuma das variáveis avaliadas (Tabela 1). A massa de frutos variou de 1,19 a $1,35 \mathrm{~kg}$, com frutos variando de 14,27 a 16,06 cm de diâmetro. Estes valores se encontram dentro da média de 1 a $2 \mathrm{~kg}$ dos frutos comerciais de abóbora do tipo 'Tetsukabuto' (Silva et al., 1999). O diâmetro e a espessura da polpa dos frutos também não diferiram quanto aos polinizadores (Tabela 1).

É interessante notar que, embora não significativo, o híbrido 'Jabras' produziu maior massa e quantidade de sementes do que o híbrido 'Tetsukabuto Kyoto', independente do polinizador utilizado. Os resultados sugerem que o acesso 'Nirvana' pode ser utilizado como polinizadora de abóboras do tipo 'Tetsukabuto'. Este acesso não diferiu da moranga 'Exposição' para nenhuma das características avaliadas. A moranga 'Exposição' é a cultivar mais utilizada para esta finalidade no Brasil. Por sua vez, 'Nirvana' (uma cultivar em fase de validação) é promissora devido a suas características de coloração laranja intensa tanto da casca quanto da polpa dos frutos, contendo teores mais elevados dos pigmentos carotenóides com ação de próvitamina A (alfa e beta-caroteno). 'Nirvana' apresenta também um conjunto de boas características organolépticas (textura, sabor e coloração da polpa). O acesso 'Nirvana' apresenta-se, desta forma, como uma nova e promissora alternativa aos produtores comerciais de abóboras híbridas, que além de utilizarem essa cultivar como polinizadora, poderão também comercializar seus frutos com preços potencialmente mais elevados. 


\section{REFERÊNCIAS}

AMARANTE CVT; MACEDO AF; ARRUDA AE. 1994. Controle de frutificação em abóbora híbrida 'Tetsukabuto'. Agropecuária Catarinense 7: 49-51.

BISOGNIN DA. 2002. Origin and evolution of cultivated cucurbits. Ciência Rural 32: 715723.

PASQUALETTO A; SILVA NF; ORDONEZ GP; BARCELOS RW. 2001. Produção de frutos de abóbora híbrida pela aplicação de 2,4-D nas flores. Pesquisa Agropecuária Tropical 31: 23-27.
PEDROSA JF; ALVARENGA MAR; FERREIRA FA; CASALI VWD. 1982. Abóboras, morangas e abobrinhas: cultivares e métodos culturais. Informe Agropecuário 8: 24-26.

PEREIRA W. 1999. Recomendações para a frutificação da abóbora híbrida tipo Tetsukabuto: Uso de polinizadores e reguladores de crescimento de plantas. Brasília: Embrapa Hortaliças. 7p. (Embrapa Hortaliças. Comunicado Técnico, 12).

PESSOA HBSV. 1998. Produção de sementes híbridas de abóbora do tipo Tetsukabuto. Brasília: Embrapa-CNPH. 9p. (EmbrapaCNPH. Circular Técnica da Embrapa Hortaliças, 12).
ROBINSON RW; DECKER-WALTERS DS 1997. Cucurbits. CAB International (Crop Production Science in Horticulture $n^{\circ}$ 6), New York, 226p.

SILVA NF; FONTES FCR; FERREIRA FA; CARDOSO A. 1999. Produção de abóbora híbrida em função de doses de fertilizante fórmula 4-14-8. Ciência e Agrotecnologia 23: 454-461.

TAVARES CAM. 1999. Abóbora Tetsukabuto. Seed News 13: 24. 